\title{
Fatores de proteção em estudantes bolsistas do Programa Universidade para Todos
}

\author{
César Leonardo Karnal \\ Universidade do Vale do Rio dos Sinos, São Leopoldo - RS - Brasil \\ Janine Kieling Monteiro \\ Universidade do Vale do Rio dos Sinos, São Leopoldo - RS - Brasil \\ Anelise Schaurich dos Santos \\ Universidade do Vale do Rio dos Sinos, São Leopoldo - RS - Brasil \\ Grace Oliveira dos Santos \\ Universidade do Vale do Rio dos Sinos, São Leopoldo - RS - Brasil
}

\begin{abstract}
Resumo
A aprovação no exame nacional para a entrada na universidade e no Programa Universidade para Todos (ProUni) não são suficientes para a manutenção e finalização da graduação no Brasil, uma vez que os estudantes têm de administrar adversidades durante o curso superior. Tais dificuldades são mais facilmente superadas diante do auxílio de algumas pessoas e situações. Este estudo objetivou caracterizar os fatores de proteção para cursar uma graduação em estudantes bolsistas do Programa Universidade para Todos provenientes de uma Instituição de Ensino Superior privada do Rio Grande do Sul. Foram pesquisados 13 alunos por meio de grupos focais. Analisaram-se as informações a partir da análise de conteúdo. Resultados destacaram a família como fator de proteção pelo apoio e incentivo concedidos aos alunos para o ingresso na graduação. Os jovens afirmaram que é necessário se planejar e ter determinação para finalizar a graduação, pois esta pode fazer diferença nas suas vidas.
\end{abstract}

Palavras-chave: Estudantes universitários; Ensino Superior; Programas educacionais.

\section{Protection Factors in Scholarship Students from the "Programa Universidade para Todos"}

\begin{abstract}
The approval of the national entrance exam in the university and in the Universidade para Todos (ProUni) are not enough to the maintenance and finalization of the graduation in Brazil, since the students have to manage adversities during the higher course. Such difficulties are more easily overcome by the help of some people and situations. This study aimed to characterize the protection factors for undergraduate scholarship students from the Programa Universidade para Todos from a Private Higher Education Institution of Rio Grande do Sul. Thirteen students were surveyed through focus groups. The information was analyzed from the content analysis. Results highlighted the family as a protection factor for the support and incentive granted to students for admission to graduation. Young people have stated that it is necessary to plan and have the determination to graduate, because it can make a difference in their lives.
\end{abstract}

Keywords: University students; Higher Education; Educational programs.

\section{Factores de protección a Estudiantes becarios del programa universidad para todos}

\section{Resumen}

La aprobación en el examen nacional para admisión a la universidad y en el Programa Universidad para Todos (ProUni) no son suficientes para la manutención y finalización del curso de grado en Brasil, una vez que los estudiantes tienen que administrar adversidades durante el curso universitario. Tales dificultades son más fácilmente superadas delante dela ayuda de algunas personas y situaciones. Este estudio se tuvo el objetivo caracterizar los factores de protección para estudiar un curso universitario en estudiantes becarios del Programa Universidad para Todos provenientes de una Institución de Enseñanza Universitaria privada de Rio Grande do Sul. Se investigaron13 alumnos por intermedio de grupos focales. Se analizaron las informaciones a partir del análisis de contenido. Los resultados destacaron la familia como factor de protección por el apoyo e incentivo concedidos a los alumnos para el ingreso en la universidad. Los jóvenes afirmaron que es necesario planearse y tener determinación para finalizar la carrera, pues esa puede hacer diferencia en sus vidas.

Palabras clave: Estudiantes universitarios; Educación Superior; Programas educacionales. 


\section{Introdução}

No âmbito da educação, o Brasil vem passando por reformulações que visam à implementação de políticas de inserção e acessibilidade principalmente no Ensino Superior (Saraiva \& Nunes, 2011). O Programa Universidade para Todos (ProUni) foi criado em 2004 e institucionalizado pela Lei $11.096 \mathrm{em} 13$ de janeiro de 2005. O objetivo desse programa é incentivar e proporcionar o ingresso da população de baixa renda em instituições privadas de Ensino Superior em todo o país (Lei n. 11.096, 2005). Além disso, a criação do ProUni visa reduzir a discrepância entre a demanda e a oferta na universidade pública (Saraiva \& Nunes, 2011), porque antes do Programa ser colocado em prática, a realidade das Instituições de Ensino Superior (IES) privadas era caracterizada pelo aumento de vagas ociosas combinadas à procura por Ensino Superior de jovens provenientes de classes socioeconômicas desfavorecidas. Por essa razão, fundamentou-se a proposta do Ministério da Educação (MEC) de estatização de vagas nas instituições particulares em troca de renúncia fiscal (Carvalho, 2006). Segundo informações do site do MEC (http://prouniportal.mec.gov.br/dados-e-estatisticas), o ProUni atingiu a marca de 1,2 milhão de bolsas concedidas para alunos de baixa renda no período de 2005 a 2013. Desse total, 873.648 foram contemplados com bolsa integral (69\%) e 400.017 com bolsa parcial (31\%).

De maneira geral, o ingresso em uma IES é uma possibilidade de ascensão social, principalmente para os jovens provenientes de classes socioeconômicas desfavorecidas. A universidade também possui uma função social de inclusão de grupos com necessidades especiais e minoritários, a fim de potencializar o acesso à cidadania (Barbosa, 2002). A partir do ProUni, as IES se organizaram para receber alunos oriundos de escolas públicas e com baixo poder aquisitivo (Libaneo, 2004; Saraiva \& Nunes, 2011). Esse programa vem ajudando muitos jovens a ascender a posições mais dignas na sociedade (Brito, 2006), já que o nível de escolaridade é reconhecido pela população em geral como pressuposto para a empregabilidade e como o diferencial no momento de colocação no mercado de trabalho (Guilland \& Monteiro, 2010; Ribeiro, 2011; Valore \& Viaro, 2007). O êxito profissional seguidamente está associado à formação em nível superior, apesar disto não garantir a inserção no mercado de trabalho (Sobrosa, Santos, Oliveira, \& Dias, 2014).

Contudo, a entrada na universidade não significa a permanência e nem a certeza de conclusão da graduação (Santos, Mognon, Lima, \& Cunha, 2011), principalmente em jovens desfavorecidos economicamente. Sabe-se que o gasto financeiro com um curso superior não se restringe apenas ao pagamento das mensalidades, pois os estudantes apresentam despesas com moradia, transporte, materiais escolares e específicos de cada curso. Para arcar com esses gastos, a maioria dos estudantes precisa trabalhar (Borges \& Coutinho, 2010). Assim, mesmo que os jovens de classes socioeconômicas desfavorecidas ingressem em um curso universitário, frequentemente não conseguem manterse no sistema por muito tempo, devido à dificuldade em con- ciliar a jornada de trabalho com as atividades relativas aos estudos (Almeida, Guisante, Soares, \& Saavedra, 2006).

Essa situação é corroborada pelo estudo de Rocha (2011), realizado com 113 alunos bolsistas do ProUni de uma universidade comunitária localizada no Rio Grande do Sul. Os participantes da pesquisa relataram apresentar dificuldade de prosseguirem a sua formação acadêmica com tranquilidade, pois precisaram buscar uma fonte de renda, seja no mercado formal ou informal, para se sustentar. O estágio remunerado adquiriu grande importância para muitos desses alunos. Os acadêmicos relataram contentamento por estudar em uma universidade privada, o que somente foi possível em virtude de terem sido contemplados com a bolsa do ProUni. Referiram que o ingresso em um curso superior poderia fazer uma diferença significativa em suas vidas, principalmente em termos econômicos e sociais (Rocha, 2011).

Além das dificuldades financeiras, os jovens desfavorecidos economicamente tendem a enfrentar obstáculos de adaptação ao contexto acadêmico, assim como a maioria dos jovens que ingressam na universidade (Teixeira, Dias, Wottrich, \& Oliveira, 2008). A transição do ensino médio para o ensino superior traz consigo modificações nos métodos de ensino, nos relacionamentos e vínculos estabelecidos, nos papéis sociais e na rotina dos estudantes. Todas essas alterações exigem flexibilidade por parte dos estudantes para se adaptarem às responsabilidades do novo ambiente (Tavares, 2012).

No processo de adaptação a um contexto até então desconhecido pelo jovem, como a universidade, destaca-se a necessidade dos fatores de proteção para o êxito no ajustamento a esse novo ambiente. Os fatores de proteção referem-se a influências que modificam, melhoram ou alteram respostas pessoais a determinados riscos de desadaptação. Tais fatores estão condicionados a ter um efeito ou influência somente quando existe a presença de um evento estressor. Entre os fatores protetivos, destaca-se a existência de uma rede de apoio social, abrangendo recursos individuais e institucionais, que encoraje e auxilie a pessoa a lidar com as circunstâncias adversas da vida (Poletto \& Koller, 2008). Em relação aos estudantes que recebem bolsa do ProUni, não foram encontrados estudos sobre os fatores protetivos. Por isso, este artigo teve como objetivo caracterizar os fatores de proteção para cursar uma graduação em estudantes bolsistas do Programa Universidade para Todos provenientes de uma Instituição de Ensino Superior privada do Rio Grande do Sul.

\section{Método}

O método utilizado foi o qualitativo de caráter exploratório e transversal. A pesquisa qualitativa tem por objetivo analisar as experiências de indivíduos ou grupos (Gibbs, 2009).

\section{Participantes}

Participaram da pesquisa 13 discentes de graduação, sendo oito mulheres e cinco homens, com idades entre 
19 e 40 anos de uma universidade privada do Rio Grande do Sul que recebiam bolsa integral do ProUni. Foram critérios de inclusão: ser maior de 18 anos, estudar na modalidade presencial e estar regularmente matriculado na cidade sede da Universidade.

No momento da realização da pesquisa, a instituição de origem dos participantes contava com mais de 3.700 alunos com bolsas parciais e integrais $(50 \%$ ou $100 \%)$ do governo federal. No segundo semestre de 2014, 2.795 alunos recebiam bolsa integral e 906 alunos bolsa parcial, segundo dados da Diretoria de Ação Social (DAS), órgão da instituição responsável pelo gerenciamento do ProUni.

\section{Instrumentos}

O instrumento de coleta de dados utilizado foi o grupo focal, técnica derivada de trabalhos com grupos em que os participantes são selecionados conforme critérios relacionados ao problema de pesquisa, os quais possibilitam discutir as questões que são sugeridas pelo pesquisador que coordena o grupo (Gatti, 2005).

Os grupos focais seguiram um roteiro semiestruturado, com questões norteadoras, por meio das quais foram investigadas duas grandes áreas. Uma delas foi a entrada na universidade, que buscou entender questões relacionadas (1) à escolha pelo curso de graduação, (2) ao apoio recebido para essa escolha, (3) ao acolhimento na instituição, (4) à adaptação à universidade e (5) a possíveis mudanças na vida após o ingresso no Ensino Superior. A outra área investigada diz respeito às vivências/experiências na IES, a qual procurou compreender (1) a interferência na vida pessoal dos fatores positivos e negativos vivenciados no Ensino Superior e (2) as estratégias que o estudante utiliza para conciliar o estudo com outras atividades. Também foi aplicado um questionário de dados sócio demográficos para levantamento dedados de identificação e de satisfação com o curso escolhido.

\section{Procedimentos de pesquisa e éticos}

O primeiro contato realizado foi com a Diretoria de Ação Social (DAS) da universidade pesquisada, explicando os objetivos da pesquisa e pedindo auxílio para o acesso aos dados dos alunos. Foi solicitada e recebida uma carta de anuência da instituição, autorizando a realização da pesquisa. Ao mesmo tempo foi fornecida uma planilha com as informações de contatos dos alunos que recebiam bolsas integrais. Depois disso, foi realizado um sorteio para selecionar os participantes da pesquisa.

A partir do sorteio, foram enviados 40 e-mails convidando os alunos a participarem da pesquisa (20 homens e 20 mulheres). Um grupo pequeno de alunos respondeu a esse e-mail. Para aqueles que não retornaram via correio eletrônico foi realizado contato telefônico, após cinco dias, convidando para a pesquisa e explicando a importância des- ta. Dois dias antes da realização de cada grupo focal, foi enviado um novo e-mail e SMS (mensagem de texto) para cada participante, relembrando o dia, o horário e o local de realização do grupo focal. No total, 16 alunos aceitaram participar da pesquisa e 13 prounistas compareceram nos dias e horários dos grupos focais.

Foram realizados dois grupos focais, sendo que em cada um participaram alunos diferentes (sete estudantes em um grupo e seis em outro). Cada grupo focal teve duração de 1 hora e 20 minutos. Antes dos grupos, foi feito um contrato verbal de sigilo, explicando que os resultados seriam apresentados de forma genérica, sem nomes divulgados. Os grupos focais foram registrados por meio de gravação de áudio e vídeo e contaram com a participação de uma observadora (graduanda em Psicologia e assistente de pesquisa), a qual realizou a posterior transcrição das informações concedidas pelos participantes. Os grupos ocorreram nas dependências da universidade em horário vespertino.

Este estudo foi encaminhado ao Comitê de Ética em Pesquisa (CEP) da Universidade na qual foi realizada a pesquisa e recebeu a aprovação de número 847.340. Foram observados todos os procedimentos éticos para pesquisa com seres humanos, seguindo as resoluções 466/2012 do Conselho Nacional de Saúde (Resolução $\left.n^{\circ} 466,2012\right)$ e 016/2000 do Conselho Federal de Psicologia (Conselho Federal de Psicologia [CFP], 2000). A coleta de dados somente ocorreu após aprovação do projeto pelo CEP mencionado.

Foram esclarecidas possíveis dúvidas antes da realização do grupo ${ }^{1}$. Foi combinado que o pesquisador comunicaria aos participantes, por e-mail, a data de defesa da dissertação e/ou disponibilizaria o link com o acesso à pesquisa concluída. Após o término da pesquisa, também foi entregue uma cópia do relatório para o gerente da DAS da universidade pesquisada.

\section{Análise de dados}

Para análise dos dados, considerando a totalidade das transcrições e registros do grupo focal, foi utilizada a técnica de análise de conteúdo de Bardin (1977). Foram realizadas três etapas: (1) pré-análise (com a organização do material como corpus da investigação), (2) exploração do material (leitura exaustiva do material, orientada pelos objetivos, na qual se buscaram sínteses coincidentes e divergentes de ideias), e (3) tratamento de resultados (realizou-se a organização de categorias emergentes a partir da leitura do material, buscando-se estabelecer relações e conexão das ideias, as quais foram posteriormente confrontadas com a revisão de literatura).

\footnotetext{
1 O Termo de Consentimento Livre e Esclarecido (TCLE) foi lido e explicado aos participantes, no qual foi informado que suas identidades seriam preservadas e que sua desistência não lhes acarretaria em qualquer prejuízo. Cada participante assinou uma via e levou consigo uma cópia do TCLE. Depois disso, responderam ao questionário sociodemográfico.
} 
As categorias foram definidas tendo em vista os objetivos e o corpus produzido nos relatos dos grupos, o que originou categorias e subcategorias. Essas foram desenvolvidas a partir das seguintes questões realizadas nos grupos: "Comente como foi o seu processo de decidir fazer uma graduação", "Você recebeu/recebe apoio de alguém para fazer a graduação?", "Comente sobre o início na Universidade, como você foi acolhido na Instituição?", "Fale-me sobre o que mudou na sua vida com a entrada na Universidade?", "Cite os fatores positivos em relação a sua vivência na Instituição e qual a interferência desses fatores na sua vida e na sua saúde".

Fez-se a opção de avaliar os fatores de proteção como processo, considerando as diferentes etapas da vivência acadêmica do estudante: a opção por fazer um curso universitário, a entrada e o processo de adaptação, a vivência atual na universidade e as perspectivas futuras. Para uma revisão final das categorias elencadas, foram utilizados dois juízes, os quais serviram para validar a divisão, os conteúdos e os nomes das categorias.

\section{Resultados}

Primeiramente serão apresentadas as principais características dos participantes com intuito de demonstrar o contexto e as particularidades dos estudantes prounistas pesquisados. Os cursos dos alunos investigados foram Arquitetura e Urbanismo; Ciência da Computação; Direito; Economia; Engenharia Civil; Letras; Logística; Nutrição; Psicologia e Publicidade e Propaganda. Todos os alunos se declararam solteiros e naturais do Rio Grande do Sul e dois alunos informaram que tinham filhos (um filho cada).

Com relação ao período do curso, os alunos se encontravam do segundo ao sétimo semestre, tendo de 5 a 100 créditos concluídos. No que se refere ao turno em que estudavam, oito alunos informaram frequentar totalmente o período noturno, quatro alunos mais noturno do que diurno e um aluno mais diurno do que noturno.

Seis alunos fazem estágio e/ou trabalham, variando a carga horária de 20 a 40 horas semanal. Oito estudantes responderam que atuam dentro de sua área de formação, quatro alunos não atuam dentro da sua área e um aluno não informou. Dois alunos participam de pesquisa de iniciação científica na universidade.

Com relação à satisfação com o curso escolhido, as notas variaram de 7 a 10, sendo que três alunos informaram a nota 10. Quatro alunos participavam de atividade voluntária. Todos os alunos informaram que tinham pessoas significativas com que podiam contar na maioria das situações diárias. Foram citados namorados(as), noivo, filho, mãe, irmãos, tios, amigos, pai e família. Cinco alunos destacaram a mãe como pessoa significativa. Três alunos moram apenas com a mãe. Apenas um aluno mora sozinho. Os outros citaram que residem com pai e filho ou pais e mãe e irmãos.

\section{A opção por fazer um curso universitário}

Nesta categoria foram elencadas questões iniciais que contribuíram para a escolha pelo curso superior e por concorrer a uma bolsa integral do ProUni. A partir disso, emergiram as subcategorias: (1) Apoio percebido e (2) Experiência de conquistar uma bolsa do ProUni.

$\mathrm{Na}$ subcategoria "Apoio percebido" verificou-se que os participantes destacaram a importância do incentivo e apoio social recebidos de pessoas significativas na sua trajetória de vida:

Então desde pequena eu trabalhava na roça, carpindo mesmo, fazendo o trabalho braçal. E meus pais sempre me incentivaram, assim, dizendo "é, esse trabalho é difícil, então procura estudar". Sempre tive muito incentivo deles, e eu fui crescendo com esse sentimento.

Mas a gente via que na escola (Ensino Médio) os professores incentivavam a fazer faculdade. Era uma coisa pra gente normal, sair do Ensino Médio e já entrar numa graduação.

Na segunda subcategoria, denominada "Experiência de conquistar uma bolsa do ProUni", os discentes contaram sua trajetória para conseguir uma bolsa integral. Eles relataram que tiveram de enfrentar diversos desafios, mas mantiveram a vontade de ingressar em um curso superior:

Daí eu iniciei o curso em 2010, inicialmente pagando, pagando com o seguro-desemprego a cadeira e daí depois eu fiz o ENEM de novo, em 2010.

Eu também fiz o ENEM três vezes, perdi a data de inscrição. No primeiro eu passei e quando eu vi, já tinha encerrado o prazo pra entregar a documentação. No segundo eu rodei e no terceiro eu consegui a bolsa.

Os prounistas também descreveram o alívio e a alegria de conseguirem uma bolsa integral, revelando que os esforços para ingressar em uma universidade privada foram alcançados.

E o ProUni trouxe isso, se não fosse o ProUni eu não estaria aqui certamente. Estaria terminando a História que é uma paixão (primeiro curso iniciado) porque é a área das Ciências Humanas, ao qual eu me identifico muito. Eu quero posteriormente depois terminar, mas o Direito seria difícil.

Só que assim, eu vi aquela bola, aquela bolinha verde do lado assim... Eu juro, sério, eu falo as pessoas não acreditam... Eu desliguei o computador, liguei de novo, sai, voltei, tá,tava verde, desliguei o computador, desliguei tudo e iniciei... voltei, tá verde, tá verde, eu comecei a gritar... 


\section{O processo de adaptação/acolhimento do prounista}

Nesta categoria foram abordados aspectos iniciais que contribuíram para o processo de entrada e adaptação dos prounistas no curso superior. Os participantes do grupo comentaram sobre os primeiros momentos na universidade e como perceberam o acolhimento e o apoio nessa situação. Foram relatadas as percepções sobre o acolhimento destinado aos novos alunos pela instituição:

Desde o primeiro momento, todo o auxílio que eu precisei que eu liguei informação disso, informação daquilo.

Foi tranquila a acolhida, foi junto com os colegas, os professores e toda assistência técnica da Universidade. Algo imenso assim.

Além do apoio da universidade, os discentes relataram terem recebido auxílio por parte dos professores para atender às primeiras exigências burocráticas e emocionais da graduação. Os participantes dos grupos também discutiram a importância do papel do coordenador na primeira matrícula, conhecida como "matrícula orientada" na universidade. O coordenador recebe os alunos e familiares, faz uma breve apresentação do curso e orienta sobre as disciplinas ideais para cursar no primeiro semestre. Após, acompanha os alunos até o setor de matrículas para a efetivação destas.

Os professores, pelo menos do meu curso assim, eu não posso falar pelos dos outros, mas os meus, todo o apoio.

No meu caso tava o coordenador do curso lá e ele também falava o curso é assim, assim, no primeiro semestre tu pega tais e tais cadeiras pra ti se habituar e tudo mais e foi mais pra guiar o que se fazer nas dificuldades.

\section{A vivência atual na universidade}

Nesta categoria, os alunos relataram como estavam vivenciando o período em que se encontravam na época da coleta da pesquisa e os fatores que contribuíam para a continuidade da vida acadêmica. Destacaram-se as subcategorias: (1) Reconhecimento; (2) Determinação; e (3) Rede de apoio.

Na primeira subcategoria, intitulada "Reconhecimento", emergiram falas emocionadas dos participantes, quando relataram que inicialmente os pais não tinham muita ideia do que era uma graduação e reconheceram, em um segundo momento, o esforço do filho. Alguns participantes relataram que são os primeiros da família a cursar uma graduação.

Mas agora eles, os meus pais agora estão felizes que eu esteja fazendo faculdade, porque eles sabem que não é mais tão fácil ter um futuro lá fora sem alguma graduação, sem alguma pós. Assim eles ficam felizes que eu esteja fazendo.
Agora, eu sou Deus na minha família.

Além disso, foi mencionado o reconhecimento intelectual dos pares, os alunos pesquisados abordaram a satisfação em serem considerados alunos com um diferencial pelos colegas e serem reconhecidos como ótimos estudantes, porque foram aprovados no ENEM.

As pessoas quando tu fala que é bolsista $100 \%$, as pessoas já te jogam lá em cima achando que tu é um gênio.

Quando é trabalho em grupo eles (colegas) já vão "aquela ali tem Prouni $100 \%$, vamos pra ela que ela tirou uma nota boa".

Na segunda subcategoria, nomeada "Determinação", os prounistas falaram do esforço em continuar a graduação e como administram o tempo no dia a dia.

Tu tem que ter muita força, como eu digo, tem que ter força na peruca, entendeu. Tu tem que gostar do que tu trabalha, tem que gostar do curso que tu faz, tu tem que ter muita energia, porque é muito difícil, sabe.

$E$ como a gente quer muito, a gente se vira nos 30 , né. $A$ gente se vira nos 30 pra poder dar conta, então quer dizer, tu ganhou algo, tu tem que se movimentar pra poder, pra isso dar certo. Pra ter uma continuidade, início, meio e fim do curso.

Na subcategoria "Rede de apoio", os alunos descrevem o apoio recebido dos familiares e do gestor como um fator essencial para permanecer estudando.

...mas eu tenho esse apoio dela [da chefe] também, como no semestre passado, eu consegui fazer sete cadeiras, inclusive uma de manhã à distância, liberação quando tem que fazer as provas, tempo pra fazer os trabalhos. Tudo vai se ajeitando, tem que ajeitar as coisas.

Eu boto uma placa na porta, não entre, por favor, entendeu. Então assim, a família tem que ajudar, isso é muito importante, senão tu não consegue, tá.

\section{Perspectivas futuras}

Esta categoria representa as mudanças, aprendizagens e possibilidades proporcionadas pelo curso superior, bem como as perspectivas futuras diante dessa vivência. É dividida nas seguintes subcategorias: (1) Novas possibilidades; (2) Contribuir para a sociedade e (3) Esperança.

$\mathrm{Na}$ primeira subcategoria, chamada "Novas possibilidades", os prounistas relataram o estudo como uma possibilidade de ampliar as perspectivas e terem outras visões de mundo.

É uma amplitude de horizontes pra gente. Porque tu sai daquela zona de conforto né, porque tu tá junto com a 
família enfim, ou no teu mundo pequeno e a universidade é bem maior. É como se fosse... É cosmopolita né... Porque tudo se conflui, quer dizer são todas as classes sociais, pensamentos diferentes e isso é bom porque te conflita, mas depois ao mesmo tempo te faz ver que o mundo é maior do que tu pensa e vê. Isso é legal.

E sempre com esta questão do trabalho e no trabalho eu vi que se não tivesse uma graduação, ou alguma coisa neste sentido, eu nunca ia conseguir sair. É tipo um platô, né, era o máximo que eu conseguia trabalhar e crescer na vida depois de 20,30 anos dentro de uma empresa.

Na subcategoria "Contribuir para a sociedade" apareceram falas envolvendo uma preocupação com o papel social de cada um na construção de uma sociedade melhor e mais solidária.

Eu acho que em todos os cursos, na verdade, tu tá fazendo de uma certa forma, a diferença na sociedade. De certa forma tu tá devolvendo, pelo menos o que o Estado, ou a própria população tá te dando em tese.

Eu quero olhar o outro como o meu igual e poder ajudar, sabe? E o Direito como qualquer outro curso, a gente pode construir uma sociedade. Eu não to falando isso pra ah... Pode ser uma utopia, mas eu acho que eu tenho que começar, eu tenho que fazer a minha parte.

Na terceira e última subcategoria, "Esperança", os alunos comentaram que o fato de cursar graduação pode proporcionar um futuro melhor e com possibilidades de ascensão profissional.

A minha mochila era uma sacolinha de açúcar, minha mãe amarrava uma sacolinha de açúcar e um cadarço (para ir para a escola). Então eu carreguei isso comigo, sempre dizendo, um dia eu vou melhorar, um dia eu vou estudar, um dia eu vou pra faculdade.

É uma visão pessoal minha, sabe? Eu não quero fazer faculdade pra viver sempre no mesmo lugar. Eu quero ir o mais além possível.

\section{Discussão}

Diante do objetivo principal, que foi caracterizar os fatores de proteção para cursar uma graduação em estudantes bolsistas do Programa Universidade para Todos provenientes de uma Instituição de Ensino Superior privada do Rio Grande do Sul, evidenciou-se o papel relevante da família durante o processo de escolha e vivência de uma graduação. De modo geral, os estudantes consideraram, de forma significativa, a opinião da família no momento de escolher a graduação que iriam cursar. Isso vai ao encontro da literatura sobre orientação profissional, uma vez que se sabe que a implementação de decisões de carreira é permeada por uma atuação direta ou indireta dos pais, seja por meio da relação que estabelecem com os filhos ou das atividades que desempenham (Carvalho \& Taveira, 2012).

Os participantes também ressaltaram o apoio (afetivo e financeiro) que receberam dos pais principalmente no início do curso de graduação. Na maioria dos casos, é na família que o jovem encontra suporte financeiro para a realização do seu projeto profissional. Muitos vivem na casa dos pais, não trabalham e, geralmente, continuam assim até concluir os estudos e/ou conseguirem um emprego. Diante dessa realidade, é possível entender o motivo de alguns jovens sentirem dificuldades para enfrentar seus pais, caso sua escolha não seja aquela esperada por eles (Santos, 2005).

Ressalta-se que escolher um curso superior é um projeto de vida (Levenfus \& Soares, 2009) e a maior parte do grupo estudado conseguiu concretizá-lo. A escolha profissional é entendida como o modo que o sujeito opta para se inserir no mundo, e por meio da profissão escolhida, modificá-lo. Quem decide por seguir determinada profissão está pensando em qual sentido que pretende dar para a sua vida, já que, ao escolher uma profissão, as pessoas traduzem a visão que têm de si em termos ocupacionais e é o desempenho desse papel ocupacional que permitirá ao indivíduo tornar-se quem deseja ser (Savickas, 2002). Portanto, a escolha profissional permeia não só a satisfação laboral, mas também a satisfação pessoal (Almeida \& Pinho, 2008; Barreto \& Aiello-Vaisberg, 2007; Gabel \& Soares, 2006).

Após os alunos prounistas escolherem um curso de graduação, eles precisam preparar-se para participar do Exame Nacional do Ensino Médio (ENEM). Geralmente, os alunos disputam várias vezes até conseguir a aprovação nesse exame. A cada ano cresce o número de candidatos para a sua realização, sendo que no ano de 2014 quase oito milhões de alunos se inscreveram (MEC, 2015). Essas tentativas no ENEM exigem determinação, planejamento e esforço, pois os alunos estudam por conta própria e no pouco tempo de que dispõem. Ter a documentação em dia depois da aprovação é uma segunda condição para cumprir os prazos das universidades. Muitas vezes, os alunos têm que ser ágeis para cumprir todas as exigências legais.

Ser o primeiro da família a cursar uma graduação evidencia orgulho em estar estudando e abrir possíveis caminhos futuros para os outros (da família, amigos e vizinhos), mas também traz o desafio de entrar no mundo acadêmico com pouca ou nenhuma referência de pessoas próximas (Rocha, 2011). Esse impacto pode ser minimizado se na entrada na graduação a organização da universidade auxiliar os alunos prounistas nas primeiras semanas de aula, tanto na localização física quanto nas orientações de matrícula. Ter um coordenador que se coloque como referência tende a tranquilizar os alunos e aproxima a coordenação do corpo discente.

Sabe-se que certas características contextuais das IES facilitam a adaptação do aluno ao ambiente acadêmico (Soares, Poubel, \& Mello, 2009). É responsabilidade da instituição fornecer informações aos universitários sobre o 
contexto acadêmico e as suas normas. Além disso, ela deve auxiliar os estudantes a usufruir sem dificuldades dos benefícios que a universidade pode lhes oferecer, por exemplo, bibliotecas, restaurante universitário, unidades e serviços e bolsas de Iniciação Científica (Igue, Bariani, \& Milanesi, 2008; Teixeira \& cols., 2008).

De fato, a ausência de orientação em relação aos processos burocráticos universitários é percebida pela maioria dos estudantes como um dos principais obstáculos à adaptação ao meio universitário, já que dificulta a ambientação à instituição e à sua rotina. As primeiras exigências universitárias burocráticas, como confirmação de vaga, matrícula e carteiras estudantis, podem fazer com que alguns acadêmicos se sintam perdidos frente ao cotidiano universitário (Teixeira \& cols., 2008). É evidente a relevância que um contexto acadêmico bem estruturado, em termos de informação e de apoio, tem para o ajustamento ao curso universitário e, consequentemente, à vida acadêmica. $\mathrm{O}$ ambiente e a cultura organizacional da instituição repercutem no desenvolvimento e desempenho do estudante, da mesma forma que aspectos estruturais, como tamanho e condições dos prédios e laboratórios, e recursos eletrônicos disponíveis (Igue \& cols., 2008; Teixeira \& cols., 2008).

Neste estudo também se evidenciou que ter mais tranquilidade financeira permite que o prounista possa permanecer na universidade e não necessite buscar alternativas para obter os subsídios para a sua sobrevivência diária. Ao pensar sobre isso, foram criados os serviços de atendimento a universitários, cuja finalidade é dar assistência social, econômica, física e psicológica aos acadêmicos (Assis \& Oliveira, 2011). Assim, iniciativas desenvolvidas nas áreas de moradia, de alimentação, de transporte, de assistência à saúde, de inclusão digital, de cultura, de esporte e de apoio pedagógico são ações voltadas para a assistência estudantil (Assis \& Oliveira, 2011). Eventualmente, a família de origem pode auxiliar nesses gastos, mas, no caso dos participantes desta pesquisa, a manutenção na graduação dependia primordialmente do próprio aluno.

Outra questão significativa que apareceu nos grupos foi o reconhecimento intelectual dos pares com os prounistas. Não apareceram situações de discriminação por serem bolsistas, as quais frequentemente estão presentes em alunos cotistas, por exemplo, que se esforçam durante toda a graduação para provarem para os pares que frequentam o ensino superior por mérito (Nery \& Costa, 2009). Ao contrário, os próprios colegas reconheciam o esforço cognitivo dos prounistas para alcançar uma boa colocação no Enem. Os alunos regulares (não bolsistas) buscavam maior proximidade nos trabalhos em grupos e avaliações com os bolsistas, pois os percebiam com um diferencial de inteligência. Outra forma de reconhecimento apontada pelos participantes vem da família e/ou da comunidade, ambas salientadas pelo fato deles conseguirem estudar em uma graduação e isso apresentar status perante a sociedade.

Diante do fato de que a maioria dos estudantes prounistas precisa trabalhar (Borges \& Coutinho, 2010) para o seu sustento, foi constatado que a relação entre o contexto de trabalho e o apoio ao estudo auxiliam na permanência no curso. Nesse sentido, ter o apoio da gestão imediata durante o ensino superior foi relatado por vários alunos dos grupos como um fator para conseguir dar continuidade à graduação. Esse apoio pode ocorrer por meio de uma flexibilização de horários no trabalho em momentos críticos durante o semestre ou mesmo na reorganização no horário de trabalho para encaixar as disciplinas ofertadas pela universidade em cada semestre.

Toda a caminhada dos prounistas, antes e durante a graduação, tem objetivos explícitos: de se formarem, melhorar a sua perspectiva de vida, contribuírem para um futuro melhor e uma sociedade mais solidária. Ter uma expectativa de poder concluir o curso é mais um aspecto que auxilia os alunos a persistirem na sua caminhada.

\section{Considerações finais}

Este artigo teve como objetivo caracterizar os fatores de proteção para cursar uma graduação em estudantes bolsistas do Programa Universidade para Todos provenientes de uma Instituição de Ensino Superior privada do Rio Grande do Sul. O ENEM possibilitou a entrada de inúmeros jovens nas universidades privadas, os quais teriam pouco ou nenhum acesso ao ensino superior. A dificuldade seguinte é a manutenção desses jovens estudando nas IES. Nesta pesquisa, percebeu-se que os jovens demonstraram contentamento por estarem estudando em uma universidade privada, graças ao auxílio da bolsa ProUni, mas também estavam cientes das dificuldades encontradas e das suas limitações por não conseguirem se dedicar em caráter integral aos estudos.

Apesar de não ser o foco dessa análise, na pesquisa que deu origem a este artigo destacaram-se fatores de risco para seguir estudando, como falta de apoio e de referência dos pais, ensino público deficitário, necessidade de manter-se economicamente e de conciliar estudo e atividades de trabalho, limitações pedagógicas, entre outros. De um modo geral, os participantes demonstraram ter clareza nos seus objetivos de vida e dar importância à continuidade na graduação. Apesar das preocupações e das dificuldades, referiram que o ingresso em um curso de graduação pode fazer uma diferença significativa nas suas vidas em termos financeiros e sociais.

Entrar em um espaço acadêmico exige investimento pessoal e energia por parte dos alunos. Não é apenas um mundo de conhecimento que está sendo apresentado, mas um espaço que vai demandar autonomia e responsabilidade dos discentes. Os dados indicaram que os fatores de proteção podem estar presentes na vivência acadêmica de qualquer aluno prounista. Esses podem atuar - individualmente ou de forma combinada - com outros fatores para auxiliar, de forma positiva, a caminhada durante a graduação.

Dessa forma, pode-se considerar que o ProUni tem função importante na acessibilidade ao ensino superior de classes socioeconômicas desfavorecidas, gerando expectativas e possibilidades de ascensão profissional e pessoal. 
No entanto, existem dificuldades e críticas que merecem atenção do governo federal, bem como das políticas públicas de ampliação ao acesso ao ensino superior, visando potencializar a efetividade da sua proposta.

Este estudo espera motivar mais pesquisadores a aprofundarem os conhecimentos sobre os fatores de proteção em universitários em situação de vulnerabilidade. A partir dos resultados alcançados, almeja-se pensar em programas preventivos para futuros alunos prounistas, identificando e auxiliando os jovens a enfrentarem as adversidades inerentes ao ingresso no Ensino Superior, fortalecendo os vínculos com a universidade. Espera-se também que esta pesquisa possa trazer subsídios que auxiliem na capacitação de uma equipe multidisciplinar para acompanhar os alunos, sejam eles prounistas ou não, na continuidade de sua vivência acadêmica.

Por fim, ressalta-se que esta pesquisa foi realizada com um grupo de estudantes específicos. Possivelmente, alunos prounistas de outras regiões e universidades apresentem vivências acadêmicas diferentes das relatadas neste estudo, o que pode fazer com que se utilizem de outros fatores de proteção para enfrentar as dificuldades. Por isso, sugere-se a realização de mais pesquisas, tanto qualitativas quanto quantitativas, para entender melhor essa realidade e auxiliar na promoção de saúde mental desse grupo durante a sua vivência acadêmica.

\section{Referências}

Almeida, L.S., Guisante, M.A., Soares, A. P., \& Saavedra, L. (2006). Acesso e sucesso no ensino superior em Portugal: questões de género, origem sócio-cultural e percurso acadêmico dos alunos. Psicologia: Reflexão e Crítica, 19(3), 507-514. Doi: 10.1590/ S0102-79722006000300020

Almeida, M.E.G.G. \& Pinho, L.V. (2008). Adolescência, família e escolhas: implicações na orientação profissional. Psicologia Clínica, 20(2), 173-184. Doi: 10.1590/S0103-56652008000200013

Assis, A.D. \& Oliveira, A.G.B. (2011). Vida universitária e saúde mental: atendimento às demandas de saúde e saúde mental de estudantes de uma universidade brasileira. Cadernos Brasileiros de Saúde Mental, 2(4-5), 159-177. Recuperado: 11 jul. 2015. Disponível: http://incubadora.periodicos.ufsc.br/index.php/cbsm/ article/view/1113.

Barbosa, M.M. (2002). A inclusão e a diversidade no ensino superior. Educação e Mudança, 9(10), 15-29.

Bardin, L. (1977). Análise de conteúdo. São Paulo: Martins Fontes.

Barreto, M.A. \& Aiello-Vaisberg, T. (2007). Escolha profissional e dramática do viver adolescente. Psicologia \& Sociedade, 19(1), 107-114.Doi: 10.1590/S0102-71822007000100015

Borges, R.C.P. \& Coutinho, M.C. (2010). Trajetórias juvenis: Significando projetos de vida a partir do primeiro emprego. Revista
Brasileira de Orientação Profissional, 11(2), 189-200. Recuperado: 11 jul. 2015. Disponível: http://pepsic.bvsalud.org/scielo. php?script=sci_arttext\&pid=S1679-33902010000200004\&lng=pt\& $\mathrm{nrm}=$ iso\&tlng=pt.

Brito, M.M.L. (2006). Juventude, pobreza e trabalho: desafios para o mundo contemporâneo. Dissertação de mestrado, Universidade Estadual do Ceará, Fortaleza, CE, Brasil.

Carvalho, C.H.A. (2006). O ProUni no Governo Lula e o Jogo Político em torno do Acesso ao Ensino Superior. Educação \& Sociedade, 27(96), 979-1000. Doi: 10.1590/S0101-73302006000300016

Carvalho, M. \& Taveira, M.C. (2012). A implementação de decisões vocacionais: revisão da literatura. Revista Brasileira de Orientação Profissional, 13(1), 27-35. Recuperado: 12 jul. 2015. Disponível: http://pepsic.bvsalud.org/scielo.php?script=sci_arttext\&pid =S1679-33902012000100005.

Conselho Federal de Psicologia [CFP] (2000). Resolução $n$. 016/2000, de 20 de dezembro de 2000. Dispõe sobre a realização de pesquisa em psicologia com seres humanos. Brasília: CFP.

Gabel, C.L.M. \& Soares, D.H.P. (2006). Contribuições da Terapia Familiar Sistêmica para a Escolha Profissional. Revista Brasileira de Orientação Profissional, 7(1), 57-64. Recuperado: 12 jul. 2015. Disponível: http://pepsic.bvsalud.org/scielo.php?script=sci_arttext \&pid=S1679-33902006000100007.

Gatti, B.A. (2005). Grupo focal na pesquisa em ciências sociais e humanas. Brasília: Líber Livro.

Gibbs, G. (2009). Análise de dados qualitativos. Porto Alegre: Artmed.

Guilland, R. \& Monteiro, J.K. (2010). Jovens e desemprego: estado da arte. Psicologia: Organizações e Trabalho, 10(2), 145-158. Recuperado: 12 jul. 2015. Disponível: https://periodicos.ufsc.br/ index.php/rpot/article/view/22215.

Igue, E.A., Bariani, I.C.D., \& Milanesi, P.V.B. (2008). Vivência acadêmica e expectativas de universitários ingressantes e concluintes. Psico-USF, 13(2), 155-164. Doi: 10.1590/S141382712008000200003

Lei $n^{\circ} 11.096$ de 13 de janeiro de 2005 (2005, 13 de janeiro). Institui o Programa Universidade para Todos - PROUNI, regula a atuação de entidades beneficentes de assistência social no ensino superior; altera a Lei no 10.891, de 9 de julho de 2004, e dá outras providências. DF: Presidência da República, Casa Civil, Subchefia para Assuntos Jurídicos

Levenfus, R.S. \& Soares, D.H.P (2009). Orientação Vocacional Ocupacional. Porto Alegre: Artmed.

Libanio, J.B. (2004). Jovens em tempos de pós-modernidade: considerações socioculturais e pastorais. São Paulo: Loyola. 
Ministério da Educação [MEC] (2015). ProUni - Dados e Estatísticas. Recuperado: 20 jul. 2015. Disponível: http://prouniportal.mec.gov. br/dados-e-estatisticas

Nery, M.P. \& Costa, L.F. (2009). Política afirmativa racial: polêmicas e processos de identidade do cotista universitário. Psico-USF, 14(2), 211-220. Doi: 10.1590/S1413-82712009000200010.

Poletto, M. \& Koller, S.H. (2008). Contextos ecológicos: promotores de resiliência, fatores de risco e proteção. Estudos de Psicologia, 25(3), 405-416. Doi: 10.1590/S0103-166X2008000300009.

Resolução $n^{\circ}$ 466, de 12 de dezembro de 2012 (2012, 12 de dezembro). Aprova normas regulamentadoras de pesquisas envolvendo seres humanos. DF: Ministério da Saúde, Conselho Nacional de Saúde.

Ribeiro, M.A. (2011). Juventude e trabalho: construindo a carreira em situação de vulnerabilidade. Arquivos Brasileiros de Psicologia, 63, 58-70. Recuperado: 13 jul. 2015. Disponível: http://pepsic.bvsalud.org/scielo.php?script=sci_arttext\&pid $=$ S1809-52672011000300007.

Rocha, M.A.M. (2011). Processo de inclusão ilusória: o jovem bolsista universitário. Jundiaí: Paco Editorial.

Santos, A.A.A., Mognon, J.F., Lima, T.H., \& Cunha, N.B. (2011). A relação entre vida acadêmica e a motivação para aprender em universitários. Psicologia Escolar e Educacional, 15(2), 283-290. Doi: 10.1590/S1413-85572011000200010.

Santos, L.M.M. (2005). O papel da família e dos pares na escolha profissional. Psicologia em Estudo, 10(1), 57-66. Recuperado: 13 jul. 2015 Disponível: http://www.redalyc.org/articulo. oa? $\mathrm{id}=287122081008$.

Saraiva, L.A.S. \& Nunes, A.S. (2011). A efetividade de programas sociais de acesso à educação superior: o caso do ProUni. Revista de Administração Pública, 45(4), 941-964. Doi: 10.1590/S003476122011000400003.

Savickas, M.L. (2002). Career Construction: A developmental Theory of Vocational Behavior. Em D. Brown \& L. Brooks (Orgs.), Career Choice and Development (pp.149-205). 4th Ed. San Francisco: Jossey-Bass.

Soares, A.B., Poube, L.N., \& Mello, T.V.S. (2009). Habilidades sociais e adaptação acadêmica: um estudo comparativo em instituições de ensino público e privado. Aletheia, 29, 27-42. Recuperado: 13 jul. 2015. Disponível: http://pepsic.bvsalud.org/scielo.php?script=sci arttext\&pid=S1413-03942009000100004.

Sobrosa, G.M.R., Santos, A.S., Oliveira, C.T., \& Dias, A.C.G. (2014) Perspectivas de futuro profissional para jovens provenientes de classes socioeconômicas desfavorecidas. Temas em Psicologia, 22(1), 223-234. Doi: 10.9788/TP2014.1-17.

Tavares, D.M. (2012). Adaptação ao Ensino Superior e Otimismo em Estudantes do $1^{\circ}$ ano. Dissertação de mestrado, Universidade Fernando Pessoa, Porto, Portugal.

Teixeira, M.A.P., Dias, A.C.G., Wottrich, S.H., \& Oliveira, A.M. (2008). Adaptação à universidade em jovens calouros. Psicologia Escolar e Educacional, 12(1), 185-202. Doi: 10.1590/S141385572008000100013

Valore, L.A. \& Viaro, R.V. (2007). Profissão e sociedade no projeto de vida de adolescentes em orientação profissional. Revista Brasileira de Orientação Profissional, 8(2), 57-70. Recuperado: 20 jul. 2015. Disponível: http://pepsic.bvsalud.org/scielo.php?script=sci_arttext \&pid=S1679-33902007000200006. 


\section{Sobre os autores}

César Leonardo Karnal (ckarnal@unisinos.br).

Psicólogo, Mestre em Psicologia pela Unisinos. Universidade do Vale do Rio dos Sinos (Unisinos).

Janine Kieling Monteiro (janinekm@unisinos.br)

Psicóloga, Mestre e Doutora em Psicologia pela Universidade Federal do Rio Grande do Sul (UFRGS), Docente do Programa de Pós-Graduação em Psicologia da Unisinos.

Anelise Schaurich dos Santos (anelise_ssantos@hotmail.com)

Psicóloga, Mestre em Psicologia pela Universidade Federal de Santa Maria (UFSM), Discente de doutorado de Programa de Pós-Graduação em Psicologia da Unisinos. Universidade do Vale do Rio dos Sinos (Unisinos).

Grace Oliveira dos Santos (psicologagracesantos@yahoo.com.br)

Discente de graduação do curso de Psicologia da Unisinos. Universidade do Vale do Rio dos Sinos (Unisinos).

Este manuscrito é derivado da Dissertação de Mestrado do primeiro autor. 